\title{
Studies on the thoria fuel recycling loop using triflic acid: effects of powder characteristics, solution acidity and radium behavior
}

\author{
Vaclav Tyrpekl ${ }^{1,2, *}$, Rayco Lommelen ${ }^{3}$, Tadeas Wangle ${ }^{1,4}$, Thomas Cardinaels $^{1,3}$, Koen Binnemans $^{3}$, \\ Jozef Vleugels ${ }^{4}$, Marc Verwerft ${ }^{1, *}$
}

${ }^{1}$ SCK.CEN, Institute of Nuclear Materials Science, Boeretang 200, 2400 Mol, Belgium

2 Department of Inorganic Chemistry, Faculty of Science, Charles University in Prague, Hlavova 2030, Prague 2, Czech Republic

${ }^{3}$ KU Leuven, Department of Chemistry, Celestijnenlaan 200F, Box 2404, B-3001 Leuven, Belgium

${ }^{4}$ KU Leuven, Department of Materials Engineering, Kasteelpark Arenberg 44, box 2450, B-3001 Heverlee, Belgium

*corresponding authors, tyrpekl@natur.cuni.cz, marc.verwerft@sckcen.be

Keywords: nuclear fuel; radium; solvometallurgy; scrap; thoria; triflic acid

Abstract: A convenient recycling loop is one of the key factors that will help to implement the thorium based nuclear fuel cycle in the future. Herein, a study is presented concerning the recycling loop of thoria production scrap using dissolution with trifluoromethanesulfonic (triflic) acid and recovery by precipitation with oxalic acid. The kinetics of thoria powders and pellet dissolution was assessed and compared with the THOREX process. The effect of the triflic acid concentration on the recovery yield of thorium during oxalate precipitation was examined, as well as the behavior of radium during this reaction. Finally, the effect of the triflic acid concentration on the recovered thoria morphology was investigated. The triflic acid has minimal effect on the recovery yield during oxalate precipitation even in the case of high acid concentrations. In general, the solubility of radium(II) oxalate is higher than for thorium(IV) and has a maximum at a triflic acid solution of $4 \mathrm{M}$. An interesting observation was that a stable dihydrate of thorium(IV) oxalate is formed in solution of high triflic acid concentration. It might be explained by the hygroscopic medium during precipitation 
of the oxalate. All above mentioned observations confirm the benefits of usage of the triflic acid based closed recycling loop for thorium dioxide based nuclear fuel.

\section{Introduction}

Every modern industrial process, including ceramics processing and fabrication, should include a closed loop for in-process recycling and reuse of the off-specification material. During nuclear fuel fabrication, typically about $10 \%$ of the final pellets are considered as production scrap and reused in the process as starting material [1]. For the $\mathrm{ThO}_{2}$ (thoria) based nuclear fuel cycle, the only known possibility to reuse the material is to dissolve the powder/pellet and reprecipitate $\mathrm{Th}^{4+}$ from the solution to give fresh starting powder convenient for sintering [2].

In 1970 's, the THOREX process was developed as a strategy for $\mathrm{ThO}_{2}$ dissolution. It uses a $\mathrm{HNO}_{3}$ medium and a catalytic amount of $\mathrm{HF}$ is necessary to boost up the dissolution rate. Addition of $\mathrm{Al}\left(\mathrm{NO}_{3}\right)_{3}$ helps to decrease the effect of highly corroding HF [2-4]. Recently, Lyczko et al. proved the ability of triflic acid (trifluoromethanesulfonic acid, $\mathrm{CF}_{3} \mathrm{SO}_{3} \mathrm{H}, \mathrm{TA}$ ) to dissolve $\mathrm{ThO}_{2}[5,6]$. This work was extended by Cagno et al. proving the possibility of the process to be a closed loop reusing TA (Figure 1.) [7]. Moreover, Bulemela et al. showed the ability of TA to dissolve mixed oxide fuel $\left(\mathrm{UO}_{2}-\mathrm{ThO}_{2}\right)$ and the need for highly concentrated TA in order to obtain fast dissolution kinetics [8]. The use of concentrated TA for dissolution of $\mathrm{ThO}_{2}$ can be considered as a solvometallurgical process [9]. It is worth mentioning that the TA dissolution process does not require the use HF as catalyst, so that the kinetics cannot be directly compared to the THOREX process. Recently, Cordara et al. conducted a multi-parametric study of $\mathrm{UO}_{2}$ dissolution in pure $\mathrm{HNO}_{3}$ solutions [10]. The dissolution process was characterized by three consecutive stages and mostly affected by acid concentration and temperature. The dissolution of pure $\mathrm{ThO}_{2}$ in $\mathrm{HNO}_{3}$ remains a challenge, but the dissolution process can be enhanced in the presence of trivalent elements in the lattice (e.g. $\left.\mathrm{La}^{3+}[11]\right)$ or $\mathrm{U}^{4+}$ with the ability to be oxidized to $U^{6+}[12]$. 
Taking into account the above mentioned information, high acid concentrations are needed for efficient dissolution, which can have negative consequences for the efficient recovery of thorium from the solution by precipitation with oxalic acid. Oxalates present an easy way of conversion of $\mathrm{Th}^{4+}$ from aqueous solution to oxide and finally to a pellet $[7,13,14]$.

Actinide oxalates are of primary interest in the field of chemistry of actinides due to their low solubility and easy conversion to the corresponding oxide [15]. Thorium oxalate $\operatorname{Th}\left(\mathrm{C}_{2} \mathrm{O}_{4}\right)_{2} \cdot 6 \mathrm{H}_{2} \mathrm{O}$ has a solubility product in the order of $10^{-25}$ assuring a high yield during precipitation [16]. $\mathrm{High} \mathrm{H}_{3} \mathrm{O}^{+}$ concentrations shift the equilibrium of oxalate (weak acid), while at the same time increasing the $\mathrm{Th}^{4+}$ content in the saturated solution, resulting in higher solubility product. When $\mathrm{HNO}_{3}$ is used, the thorium oxalate solubility increases not only because of the high acidity, but also by formation of soluble $\mathrm{Th}^{4+}$ - nitrate complexes $[16,17]$. The higher solubility of $\mathrm{Th}^{4+}$ oxalate might therefore lead to lower yields during the precipitation from strongly acidic solutions.

In the present work, several processes in the $\mathrm{ThO}_{2}$ recycling loop using TA were studied. At first, dissolution kinetics studies were performed describing the effect of powder/pellet characteristics on the dissolution kinetics. Secondly, the solubility of $\mathrm{Th}^{4+}$ oxalate powder in $\mathrm{HNO}_{3}$ and $\mathrm{TA}$ acid media was examined. ${ }^{228}$ Radium is the member of the ${ }^{232}$ Th decay chain responsible for the higher radioactivity of thorium materials and solutions. In order to keep the waste solution radioactivity at a minimal level, special attention was paid to the radium dissolution and co-precipitation behavior during the whole process.

\section{Experimental procedures}

All chemicals were used as received without any further purification. A $20 \mathrm{~g}$ mother batch of $\mathrm{Th}\left(\mathrm{C}_{2} \mathrm{O}_{4}\right)_{2} \cdot 6 \mathrm{H}_{2} \mathrm{O}$ was synthesized according to [14], where a $1.0 \mathrm{M}$ thorium nitrate solution (in $1.6 \mathrm{M}$ nitric acid, supplied by Solvay) was dropped into $0.75 \mathrm{M}$ oxalic acid solution at $10^{\circ} \mathrm{C}(\geq 99 \%$, SigmaAldrich, 5\% molar excess) and stirred with a impeller at $300 \mathrm{rpm}$. After precipitation, the suspension was allowed to digest for 15 minutes under stirring. The precipitate was filtered on a $0.7 \mu \mathrm{m}$ 
Whatman GF/F glass fiber filter, washed with distilled water, dried in air and crushed gently in an agate mortar. From the mother batch, small batches of $2 \mathrm{~g}$ were decomposed under ambient air to thoria at $750,850,1000$ and $1400^{\circ} \mathrm{C}$. The calcination cycle included heating and cooling rates of 5 ${ }^{\circ} \mathrm{C} . \mathrm{min}^{-1}$ and 1 hour dwell time at the desired temperatures (calcinations were performed in Nabertherm LT 9/13/P330 and Carbolite tube furnaces). BET specific surface area measurements were done using a Micrometrics Tristar 3020 apparatus, with degassing at $300{ }^{\circ} \mathrm{C}$ for 3 hours prior to each analysis.

Scanning electron microscopy (SEM, Jeol JSM 7100FA) and X-ray diffraction (XRD) were used to characterize the powders. The powders were coated with a $5 \mathrm{~nm}$ platinum layer to avoid charging. For the powder XRD analysis, a Philips X'Pert Pro diffractometer with a Cu LFF tube was used. The diffractograms were analyzed with a Le Bail fitting method using JANA 2006 software package [18]. The crystallite size and the non-dimensional strain were calculated using the Williamson-Hall method [19]. $\mathrm{LaB}_{6}$ was used as a standard to correct for instrumental peak broadening.

\section{Thoria dissolution experiments}

All the dissolution tests used 7.8 M triflic acid solutions prepared from pure triflic acid (98\% SigmaAldrich). These experiments were performed under atmospheric pressure in a dedicated setup. A silicon oil bath was heated to $195 \pm 5{ }^{\circ} \mathrm{C}$. A three-neck flask with a reflux condenser was placed in the bath and the reaction mixture was magnetically stirred. The powders were used as-received from the thermal conversion of the initial oxalate at the desired conditions. Two samples were selected for dissolution: i) pellet of $89 \%$ of the theoretical density (TD) simulating a rejected pellet with low density; ii) pellet of $98 \%$ TD representing a satisfactory density. The pellets were manually crushed to small chunks before adding them to the reaction flask. For each dissolution experiment, $101 \pm 2 \mathrm{mg}$ of powder/pellet was added to $3 \mathrm{~mL}$ of $7.8 \mathrm{M}$ triflic acid (about 1:60 molar excess of triflic acid). The reported dissolution time corresponds to the period from reaching the reflux conditions until complete dissolution was observed visually (transparent and clear solution). 


\section{Thorium(Radium) oxalate solubility studies}

The solubility of thorium(IV) oxalate was tested in both triflic acid and nitric acid. The triflic acid solutions with concentrations $7.8,3.9,0.98$ and $0.098 \mathrm{M}$ were prepared using pure triflic acid (98\% Sigma-Aldrich). Nitric acid (67-69\% Fisher Chemicals) was used to prepare nitric acid solutions of 7.3, 3.7, 0.91 and $0.091 \mathrm{M}$. A sample of $100 \pm 3 \mathrm{mg}$ of $\mathrm{Th}^{4+}$ oxalate hexahydrate (prepared as described above) was added to an $8 \mathrm{~mL}$ vial together with $5 \mathrm{~mL}$ of the desired acid. Afterwards, the mixtures were stirred with a magnetic stirrer for 3 days to reach equilibrium. The remaining solid was separated from the liquid via filtration through cotton and centrifugation (VWR collection, $5000 \mathrm{rpm}$ 10 minutes).

The concentrations of Th and Ra in the liquid phase were analyzed using $\gamma$-spectroscopy and ICP-MS. Gamma spectroscopy was done at least 4 weeks (minimum 8 half-lives of ${ }^{224} \mathrm{Ra}$ ) after separating the liquid and solid phases allowing the establishment of equilibrium between ${ }^{228} \mathrm{Th}$ and its daughters. The concentration of Ra was measured on the $338 \mathrm{keV}$ emission line of ${ }^{228} \mathrm{Ac} .{ }^{228} \mathrm{Th}$ was used as a tracer for thorium and measured on the $238 \mathrm{keV}$ line of ${ }^{212} \mathrm{~Pb}$. Activities were measured using HPGe $\gamma$ spectrometers (Canberra or Ortec). Count rates were converted to the activity using calibrated efficiencies for each detector and emission yields collected on Laraweb [14]. Errors from Laraweb were used without modification, while $2.65 \sigma$ was used for measurement errors. A long measurement time was needed (90000 seconds) because a low activity was expected. The concentration of thorium in the samples was also measured with ICP-MS on a ThermoFisher XSeries2.

\section{Precipitation and morphology studies}

As reported earlier [20], the experimental precipitation conditions from the triflic acid solution (7.8 $M$, see above) have an important effect on the morphology of the final product. Therefore, the influence of the triflic acid concentration on the morphology was further tested by diluting the solutions after dissolution $(0.14 \mathrm{M})$ with demineralized water to give three concentrations: ten times diluted, twice diluted, and undiluted. The thorium was precipitated with approximately $5 \%$ excess of 
$0.2 \mathrm{M}$ oxalic acid ( $\geq 99 \%$ Sigma-Aldrich) in a vial which was vigorously stirred. In addition, the effect of temperature was also studied by cooling all reagents to $5^{\circ} \mathrm{C}$ in an ice bath. The solutions were mixed by either dropping the oxalic acid solution into the $\mathrm{Th}^{4+}$ triflate solution ("direct strike") or dropping the $\mathrm{Th}^{4+}$ triflate solution into the oxalic acid ("reverse strike"). The solution was added at a rate of about one drop per second, while constant stirring (300 rpm) was applied. An overview of the different precipitation conditions is given in Table 1. After 10 minutes of digestion, the precipitate was separated in a centrifuge (5000 rpm, 5 minutes) and washed three times with demineralized water. The final powder was dried overnight at $50^{\circ} \mathrm{C}$ and converted to $\mathrm{ThO}_{2}$ by calcination at $750{ }^{\circ} \mathrm{C}$ with 1 hour of dwell time. The morphology of the final powder was examined by SEM.

\section{Results and discussion}

\section{$\mathrm{ThO}_{2}$ dissolution in triflic acid}

Thorium dioxide particles obtained after the thermal conversion of thorium(IV) oxalates retain the overall morphology of the parent oxalate crystals. The $\mathrm{ThO}_{2}$ crystallite size and specific surface area are mainly dependent on the calcination conditions $[13-15,21]$. The powder produced for the dissolution experiments follows this standard behaviour. It keeps the original platelet morphology of the $\mathrm{Th}^{4+}$ oxalate while decomposing into a sponge-like assembly of $\mathrm{ThO}_{2}$ nanocrystals (Figure 2 ). The size of the nanocrystals is about $37 \mathrm{~nm}$ when calcined at $750{ }^{\circ} \mathrm{C}$ and the crystallite size increases with increasing processing temperature, whereas the specific surface area decreases. Detailed information on the starting powders is provided in Table 2.

A clear difference was observed in the times required for dissolution of thoria in triflic acid and in the THOREX acid mixture. It took just a few minutes to dissolve a sample of thoria powder with a specific surface area of $2.4 \mathrm{~m}^{2} \mathrm{~g}^{-1}$ in boiling THOREX acid, whereas it took about 30 minutes to dissolve the same sample in boiling triflic acid [7]. On the other hand, such comparison, being technologically important, should be taken with care as the THOREX medium contains catalytic amounts of HF. 
Therefore, a comparison with pure nitric acid would be more relevant. It that case, the dissolution time for an analogous sample would take several hours in $4 \mathrm{M} \mathrm{HNO}_{3}$ at $90^{\circ} \mathrm{C}$, as derived from literature data [11]. The dissolution time dependence on the powder characteristics in $7.8 \mathrm{M}$ triflic acid is plotted in Figure 3, together with results obtained for sintered pellets. In Figure 3B, the pellet dissolution rates are compared with THOREX data. In general, the dissolution rates in TA are about two orders of magnitude lower than for the THOREX acid. There are more significant differences in the TA dissolution rates of pellets of different densities compared to THOREX. This fact is linked to the different dissolution mechanisms, i.e., the presence of HF governs not only the kinetics but probably also hinders the positive effect of open porosity in the THOREX process.

\section{Effect of oxalate solubility versus solution acidity on the recovery yield}

The low solubility of thorium(IV) oxalate (solubility product $\sim 10^{-25}$ ) makes this salt interesting for quantitative transfer of $\mathrm{Th}^{4+}$ from solution into the solid phase. Increases in the solubility are undesired, because it causes a decrease in the precipitation yield. Several experiments studying the solubility of thorium(IV) and radium(II)oxalate were designed to determine this effect. Figure $4 \mathrm{~A}$ shows the concentration of $\mathrm{Th}^{4+}$ measured by ICP-MS in the supernatant above solid thorium(IV) oxalate hexahydrate for different acid concentrations. On Figure 4B, similar tendencies can be found in the terms of activity, in this case for $\mathrm{Ra}^{2+}$ as well. The ICP-MS results indicate that the solubility of $\mathrm{Th}\left(\mathrm{C}_{2} \mathrm{O}_{4}\right)_{2} \cdot 6 \mathrm{H}_{2} \mathrm{O}$ is lower in triflic than in nitric acid solutions. Considering previous work $[16,17]$ and current results, the increased solubility in nitric acid solution is caused by the formation of soluble $\mathrm{Th}^{4+}$ nitrate complexes, which is not the case for the triflate anion, which is a weakly coordinating anion. The experimental results obtained in this study and the literature data however show some discrepancies in actual concentration values. Measurements of trace amounts are often very sensitive to specific manipulations and therefore the actual values should be considered with care. However, the thorium concentrations calculated from the activity measurements and measured by ICP-MS show a very good agreement. The decrease of the oxalate precipitation yield in acidic media 
was calculated for one liter of $0.1 \mathrm{M} \mathrm{Th}^{4+}$ solution (Figure 5) based on the ICP-MS data. The acidity considered should be taken for the whole solution after mixing. The yield in case of triflic acid does not fall below $99 \%$ even in highly acidic solutions, which presents an interesting advantage compared to nitric acid. The plot of thorium and radium activities in the solutions (Figure 4B) follows the trends measured by ICP-MS: the activities are higher for higher amounts of acid in the solution. But the activity of radium is significantly higher than for thorium. This can be explained by the higher solubility of radium oxalate. Indeed, the solubility of oxalates of alkaline earth metals is largely higher, the solubility product of calcium oxalate is $\sim 10^{-9}$, strontium(II) and barium(II) oxalates about $10^{-7}[22-24]$. It was assumed that the solubility of radium(II) oxalate follows the group trend reaching $10^{-7}-10^{-9}$. Unfortunately, no solubility data are available in the open literature for comparison. Another interesting observation (Figure 6 ) is that the activity ratio of $\mathrm{Ra} / \mathrm{Th}\left(\mathrm{a}_{\mathrm{Ra}} / \mathrm{a}_{\mathrm{Th}}\right)$ is similarly changing in the solution with acid concentration for both nitric and triflic acids. As reported by Wangle et al., the precipitation efficiency by oxalic acid for the initial oxalate is $99 \%$ for Th and $95 \%$ for $\mathrm{Ra}$ [14]. The measured value of the $\mathrm{a}_{\mathrm{Ra}} / \mathrm{a}_{\mathrm{Th}}$ is 0.98 , maintaining the secular equilibrium. For low acidity of the solution $(\leq 4 \mathrm{M})$, the activity of radium in the solution is several times higher than for thorium. This separation phenomenon reaches a maximum for $4 \mathrm{M}$ nitric acid. This fact might be used for the extraction of radium from solid thorium oxalate. At higher acidity, both elements are present in the solution equally close to the equilibrium state in the initial powder.

\section{Precipitation of thorium(IV) oxalate from triflic acid solutions}

Eight defined experiments were performed to study the precipitation of throium(IV) oxalate from triflic acid solution after dissolution of thoria. The experimental conditions can be found in Table 1 . Most results are confirming the classical oxalate precipitation mechanism described in literature [1315]. An interesting observation was done for experiments \#1 and $\# 2$ performed at $5{ }^{\circ} \mathrm{C}$. In both tests, separation of two liquid phases occurred after 10 minutes of digestion time and the precipitated powder settled at the interface. At $5{ }^{\circ} \mathrm{C}$, water and triflic acid appear to have a limited miscibility and 
phase separation occurs. The water-saturated triflic acid $(8 \mathrm{M})$ has a higher density than the oxalic acid $(0.2 \mathrm{M})$ solution and, hence settled at the bottom of the vial.

All thorium(IV) oxalate powders recovered from the TA dissolution experiments as listed in Table 1 were calcined at $750{ }^{\circ} \mathrm{C}$ and studied using scanning electron microscopy (Figure 7). Only samples \#7 and \#8 showed the oxalate morphology observed during precipitation from similar nitric acid media [20]. For nitric acid media, the low pH was responsible for the empty square morphology, whereas a 0.78 M TA solution was the one with the lowest acidity in the present study. The morphology of the other samples was not typical for thorium dioxide formed by oxalate conversion, which is primarily seen as square platelets.

For samples \#1 to \#6, the precipitation took place in an environment with a very high acidity. Highly concentrated triflic acid solutions and its salts are often hygroscopic $[25,26]$. Indeed, the thorium oxalate obtained at such conditions is not the typically observed hexahydrate [14], but a dihydrate (see Figure 8). The formation of $\mathrm{Th}\left(\mathrm{C}_{2} \mathrm{O}_{4}\right)_{2} \cdot 2 \mathrm{H}_{2} \mathrm{O}$ was attributed to the hygroscopic nature of the precipitation medium. Surprisingly, the dihydrate formed through this synthetic route is relatively stable in air (at ambient moisture conditions). It is well known that thorium(IV) oxalate dihydrate prepared by thermal decomposition of a hexahydrate rapidly regains the crystalline water of hydration from the air moisture [27]. Moreover, the presence of the dihydrate might explain the atypical morphology. White et al. reported melting of lowly hydrated thorium(IV) oxalate during

rapid annealing [27]. Based on this observation, it was believed that partial or complete fusion during the decomposition and conversion to the oxide might be the cause of the difference in morphology in our case.

\section{Conclusion}

The presented study is dedicated to the $\mathrm{ThO}_{2}$ recycling loop using triflic acid (TA) dissolution and recovery by oxalate precipitation. The results show slower dissolution kinetics for TA than for the THOREX mixture, but without the need of catalytic hydrofluoric acid. Since thorium does not form 
soluble complexes with the triflate anion, the solubility of thorium(IV) oxalate remains low even in high acid content solutions. This fact allows the thorium oxalate precipitation yield to be steadily high. The behavior of radium during precipitation, which is a function of the acid molarity, was assessed. The results reveal that both radium(II) and thorium(IV) oxalates dissolve in solutions with high acid content. For lower acidities, the solutions contain more radium than the anticipated equilibrium amount with a maximum around $4 \mathrm{M}$ for both TA and nitric acids. Radium is the main radioactive element of the ${ }^{232} \mathrm{Th}$ decay chain, thus the results might be interesting from the point of view of waste treatment. An important observation is that highly acidic solutions (hygroscopic) allow the formation of stable dihydrate form of thorium(IV) oxalate.

\section{Acknowledgements}

The authors are grateful to Peter Dries and Koen Vanaken (SCK·CEN) for assistance in the laboratory. We are also grateful to Lesley Adriaensen and Magda Ooms for the gamma spectroscopy measurements and Andrew Dobney and Prisca Verheyen for the ICP-MS. The company Solvay S.A. is acknowledged for the supply of thorium(IV) nitrate solution.

On behalf of all authors, the corresponding author states that there is no conflict of interest.

\section{References}

[1] IAEA-TECDOC-1115 (1999) Minimization of waste from uranium purification, enrichment and fuel fabrication, Vienna

[2] Das D, Baker RJ (2013) Thoria-based Nuclear Fuels: Thermophysical and Thermodynamic Properties, Fabrication, Reprocessing, and Waste Management. Springer Verlag, London [3] Shying ME, Carswell DJ, Florence TM (1972) Oxide Dissolution Mechanisms - II Mechanism for Thoria/Nitric/Hydrofluoric Acid System. J Inorg Nucl Chem 34:213-220 
[4] Shying ME, Florence TM, Carswell DJ (1970) Oxide dissolution mechanisms - I the role of fluoride in the thoria/nitric/hydrofluoric acid system. J Inorg Nucl Chem 32:3493-3508

[5] Lyczko K, Lyczko M, Herdzik I, Zielinska B 92011) Method of dissolution of thorium oxide. E.P. Office (Ed.) European Patent Office, EP2397443A3

[6] Lyczko K, Lyczko M, Walo M, Lipkowski J (2012) Conversion of thorium(IV) oxide into thorium(IV) trifluoromethanesulfonate: Crystal structure of thorium(IV) trifluoromethanesulfonate dihydrate. Inorg Chem Commun 24:234-236. DOI: 10.1016/j.inoche.2012.07.024

[7] Cagno S, Gijsemans L, TyrpekI V, Cardinaels T, Verwerft M, Binnemans K (2017) Use of triflic acid in the recycling of thoria from nuclear fuel production scrap. J Sust Metall 3:659-667. DOI: $10.1007 / \mathrm{s} 40831-017-0136-2$.

[8] Bulemela E, Bergeron A, Stoddard T (2016) Dissolution Study of Thorium-Uranium Oxides in Aqueous Triflic Acid Solutions. Procedia Chemistry 21:239-246. DOI: 10.1016/j.proche.2016.10.034 [9] Binnemans K, Jones PT (2017) Solvometallurgy: an emerging branch of extractive metallurgy. J Sust Metall 3:570-600. DOI: 10.1007/s40831-017-0128-2

[10] Cordara T, Szenknect S, Claparede L, Podor L, Mesbah A, Lavalette C, Dacheux N (2017) Kinetics of dissolution of $\mathrm{UO}_{2}$ in nitric acid solutions: A multiparametric study of the non-catalysed reaction. J Nucl Mater 496:251-264. DOI: 10.1016/j.jnucmat.2017.09.038

[11] Horlait D, Tocino F, Clavier N, Dacheux N, Szenknect S (2012) Multiparametric study of Th. ${ }_{x} \mathrm{Ln}_{x} \mathrm{O}_{2-x / 2}$ mixed oxides dissolution in nitric acid media. J Nucl Mater 429:237-244. DOI: 10.1016/j.jnucmat.2012.05.047

[12] Claparede L, Tocino F, Szenknect S, Mesbah A, Clavier N, Moisy P, Dacheux N (2015) Dissolution of $\mathrm{Th}_{1-\mathrm{x}} \mathrm{U}_{\mathrm{x}} \mathrm{O}_{2}$ : Effects of chemical composition and microstructure. J Nucl Mater 457:304-316. DOI: 10.1016/j.jnucmat.2014.11.094

[13] TyrpekI V, Vigier JF, Manara D, Wiss T, Dieste Blanco O, Somers J (2015) Low temperature decomposition of U(IV) and Th(IV) oxalates to nanograined oxide powders. J Nucl Mater 460:200208. DOI: 10.1016/j.jnucmat.2015.02.027 
[14] Wangle T, Tyrpekl V, Cagno S, Delloye T, Larcher O, Cardinaels T, Vleugels J, Verwerft M (2017) The effect of precipitation and calcination parameters on oxalate derived $\mathrm{ThO}_{2}$ pellets. J Nucl Mater 495:128-137. DOI: 10.1016/j.jnucmat.2017.07.046

[15] Abraham F, Arab-Chapelet B, Rivenet M, Tamain C, Grandjean S (2014) Actinide oxalates, solid state structures and applications. Coordin Chem Rev 266-267:28-68. DOI: 10.1016/j.ccr.2013.08.036 [16] Kurnakova AG, Shubochkin LK (1963) Solubility of $\mathrm{Th}\left(\mathrm{C}_{2} \mathrm{O}_{4}\right)_{2} \cdot 6 \mathrm{H}_{2} \mathrm{O}$ in aqueous $\mathrm{HNO}_{3}$ and $\mathrm{H}_{2} \mathrm{C}_{2} \mathrm{O}_{4}$ at $25^{\circ} \mathrm{C}$. Russ J Inorg Chem 8:647-650

[17] Pazhukhin EM, Smirnova EA, Krivokhatskii AS, Pazukhina YL, Kochergin SM (1985) Optimization of conditions of thorium oxalate precipitation. I. Solubility of thorium oxalate in the presence of like ions. Sov Radiochem 27:606-611

[18] Petricek V, Dusek M, Palatinus L (2014) Crystallographic Computing System JANA2006: General features. Z Krist-Cryst Mater 229:345-352. DOI: 10.1515/zkri-2014-1737

[19] Williamson GK, Hall WH (1953) X-Ray line broadening from filed aluminium and wolfram. Acta Metall. 1:22-31

[20] Tyrpekl V, Beliš M, Wangle T, Vleugels J, Verwerft M (2017) Alterations of thorium oxalate morphology by changing elementary precipitation conditions. J Nucl Mater 493:255-263. DOI: 10.1016/j.jnucmat.2017.06.027

[21] Horlait D, Clavier N, Dacheux N, Cavalier R, Podor R (2012) Synthesis and characterization of $\mathrm{Th}_{(1-}$ ${ }_{x)} \operatorname{Ln}(x) O_{(2-x / 2)}$ mixed-oxides. Mater Res Bull 47:4017-4025. DOI: 10.1016/j.materresbull.2012.08.068 [22] Qafoku O, Felmy AR (2007) Development of accurate chemical equilibrium models for oxalate species to high ionic strength in the system: Na-Ba-Ca-Mn-Sr-Cl-NO $\mathrm{N}_{3}-\mathrm{PO}_{4}-\mathrm{SO}_{4}-\mathrm{H}_{2} \mathrm{O}$ at 25 degrees $\mathrm{C}$. J Solution Chem 36:81-95. DOI: 10.1007/s10953-006-9094-1

[23] Kirgintsev AN, Nikashina TA (1966) Solubility of barium and strontium oxalates in nitric acid. Russ J Inorg Chem 11:1191-1193

[24] McComas WH, Rieman W (1942) The effect of pH on the solubility of calcium oxalate. J Am Chem Soc 64:2948-2949 
[25] Howells RD, McCown JD (1977) Trifluoromethanesulfonic acid and derivatives. Chem Rev 77:6992

[26] Subramanian LR, Martinez AG, Hanack M, Prakash GKS, Hu J (2006) Trifluoromethanesulfonic Acid". Encyclopedia of Reagents for Organic Synthesis, John Wiley \& Sons, Inc. DOI: 10.1002/047084289X.rt246.pub2

[26] Joseph K, Sridharan R, Gnanasekaran T (2000) Kinetics of thermal decomposition of Th $\left(\mathrm{C}_{2} \mathrm{O}_{4}\right)_{2} \cdot 6 \mathrm{H}_{2} \mathrm{O}$. J Nucl Mater 281:129-139. DOI: 10.1016/S0022-3115(00)00241-5

[27] White GD, Bray LA, Hart PE (1981) Optimization of thorium oxalate precipitation conditions relative to derived oxide sinterability. J Nucl Mater 96:305-313

\section{List of Figures}

Figure 1. Closed loop of the $\mathrm{ThO}_{2}$ recycling process based on triflic acid describing the dissolution (right), oxalate precipitation (top) and conversion to oxide (left), along with the recovery of triflic acid by distillation [7].

Figure 2. SEM micrographs of the $\mathrm{ThO}_{2}$ starting powders; the overall view of the agglomerated platelets (A) and detailed view of microstructural changes with increasing annealing temperature: $750{ }^{\circ} \mathrm{C}(\mathrm{B})$, $1000^{\circ} \mathrm{C}(\mathrm{C})$ and $1400{ }^{\circ} \mathrm{C}(\mathrm{D})$. In (B), the sheet-like stacking within the prior oxalate platelets is clearly visible, while this is no longer visible in (C) and (D).

Figure 3. Dependence of the dissolution time on the powder specific surface area (calcination temperature, $\mathrm{A}$ ) and comparison of the pellet dissolution rate in 7.8 M TA and THOREX process (B).

Figure 4. The concentration of $\mathrm{Th}^{4+}$ in the aqueous phase of different acid molarity in equilibrium with solid thorium(IV) oxalate hexahydrate, measured by ICP-MS together with literature data (A). The 
concentrations of ${ }^{232} \mathrm{Th}$ and ${ }^{228} \mathrm{Ra}$ calculated from the solution activity and decay chain relations in equilibrium (B).

Figure 5. Effect of an increased solubility in acidic conditions on the theoretical yields calculated for the precipitation of 1 liter of $0.1 \mathrm{M} \mathrm{Th}^{4+}$ solution by equimolar amount of oxalic acid. In this case the acidity pertains to the whole mixture after precipitation.

Figure 6. The ratio of activities $\left(a_{\mathrm{Ra}} / \mathrm{a}_{\mathrm{Th}}\right)$ in the solutions of different acid molarity, the ratio of the initial powder (red dashed line) is marked as well for illustration.

Figure 7. Morphology of recovered $\mathrm{ThO}_{2}$ annealed to $750{ }^{\circ} \mathrm{C}$. The conditions of oxalate precipitation are presented in the Table 1. Every micrograph is marked with paramount conditions affecting the reaction (direct strike DS, reverse strike RS, concentration of triflic acid [TA], temperature T) and experiment number.

Figure 8. X-ray powder diffraction of thorium(IV) oxalate obtained from a high TA content solution

\section{List of Tables}

Table 1. Experimental conditions during $\mathrm{Th}^{4+}$ oxalate precipitation from solutions obtained after dissolution of $\mathrm{ThO}_{2}$ in triflic acid.

\begin{tabular}{ccccc}
\hline \multirow{2}{*}{ \# Experiment } & \multicolumn{2}{c}{$\begin{array}{c}\text { Concentration [M] } \\
\text { Th }^{4+}\end{array}$} & $\begin{array}{c}\text { Triflic acid } \\
\text { Temperature }\left[{ }^{\circ} \mathbf{C}\right]\end{array}$ & Strike \\
\hline 1 & 0.14 & 7.8 & 5 & Reverse \\
2 & 0.14 & 7.8 & 5 & Direct \\
3 & 0.14 & 7.8 & 25 & Reverse \\
4 & 0.14 & 7.8 & 25 & Direct \\
5 & 0.07 & 3.9 & 25 & Reverse \\
6 & 0.07 & 3.9 & 25 & Direct \\
7 & 0.014 & 0.8 & 25 & Reverse \\
8 & 0.014 & 0.8 & 25 & Direct \\
\hline
\end{tabular}


Table 2. $\mathrm{ThO}_{2}$ powder characteristics for different conversion temperature and dissolution times in triflic acid under mild reflux conditions. The size range was estimated from the SEM pictures. The crystallite size and strain were calculated using the Williams-Hall plot on powder XRD data.

\begin{tabular}{cccccc}
\hline $\begin{array}{c}\text { Calcination } \\
\text { temperature } \\
{\left[{ }^{\circ} \mathrm{C}\right]}\end{array}$ & $\begin{array}{c}\text { Specific } \\
\text { surface area } \\
{\left[\mathrm{m}^{2} / \mathrm{g}\right]}\end{array}$ & $\begin{array}{c}\text { Platelet size } \\
{[\boldsymbol{\mu} \mathrm{m}]}\end{array}$ & $\begin{array}{c}\text { Crystallite size } \\
{[\mathrm{nm}]}\end{array}$ & $\begin{array}{c}\text { Strain } \\
{[\%]}\end{array}$ & $\begin{array}{c}\text { Dissolution } \\
\text { time } \\
{[\text { minutes] }}\end{array}$ \\
\hline 750 & 12 & $0.31-0.89$ & 37 & 0.08 & 6 \\
850 & 9 & $0.33-0.87$ & 56 & 0.03 & 17 \\
1000 & 7 & $0.30-0.71$ & 103 & 0.02 & 31 \\
1400 & 0 & $0.27-0.68$ & $>200$ & - & 34 \\
\hline
\end{tabular}

